\title{
ANÁLISE DA DISPENSAÇÃO DE ANTIBIÓTICOS BETA-LACTÂMICOS APÓS A RDC № 20/2011 EM UMA REDE DE FARMÁCIAS DO MUNICÍPIO DE PONTA GROSSA - \\ PARANÁ
}

\author{
ANALYSIS OF BETA-LACTAM ANTIBIOTICS DISPENSE AFTER RDC No. 20/2011 IN \\ A PHARMACY CHAIN IN THE CITY OF PONTA GROSSA, PARANÁ, BRAZIL
}

\author{
André Luis de LIMA ${ }^{1}$; Carla Regina Blanski RODRIGUES²; Edineia Gulchinski da \\ SILVA3; Elder da Rosa LEMES ${ }^{4}$; Rodrigo Moreira Caetano PINTO ${ }^{5}$; Vivian KUSANO ${ }^{6}$
}

1 - Mestrando do curso de pós-graduação em Ciências da Saúde da Universidade Estadual de Ponta Grossa - UEPG, Graduado em Farmácia pelo Centro de Ensino Superior dos Campos Gerais - CESCAGE, Ponta Grossa, PR.

2 - Mestra em Engenharia de Produção pela Universidade Tecnológica Federal do Paraná, Graduada em Farmácia e Enfermagem pela Universidade Estadual de Ponta Grossa - UEPG, Ponta Grossa, PR.

3 - Graduada em Farmácia pelo Centro de Ensino Superior dos Campos Gerais - CESCAGE, Ponta Grossa, PR. 4 - Graduando do Curso de Farmácia da UNICESUMAR de Ponta Grossa, PR, Graduado em Licenciatura Interdisciplinar em Ciências Naturais, pela Universidade Tecnológica Federal do Paraná - UTFPR, Ponta Grossa, PR.

5 - Mestre em Ciências Farmacêuticas pela Universidade Estadual de Ponta Grossa - UEPG, Graduado em Farmácia pela Universidade Estadual de Ponta Grossa - UEPG, Ponta Grossa, PR.

6 - Graduada em Farmácia pelo Centro de Ensino Superior dos Campos Gerais - CESCAGE, Ponta Grossa, PR. Autor para correspondência: dehallk@gmail.com

\section{Resumo:}

Os antibióticos podem ser compostos naturais ou sintéticos capazes de inibir o crescimento ou causar a morte de fungos ou bactérias. Além de fazerem parte dos grupos de medicamentos mais dispensados, estão também entre os fármacos que apresentam maior frequência de uso irracional no mundo. O presente trabalho aborda um estudo qualitativo e quantitativo, descritivo e de campo, que teve como objetivo realizar uma análise da dispensação de antibióticos beta-lactâmicos após a RDC 20/2011 em uma rede de farmácias do município de Ponta Grossa-PR, e identificar a percepção do cliente em relação à obrigatoriedade de prescrição para antibióticos. Foi realizado o levantamento da frequência de dispensação de antibióticos beta-lactâmicos no período referente a um ano antes e um ano depois de 16 de abril de 2013, data em que a Anvisa passou a exigir das farmácias e drogarias, a transmissão eletrônica de cada venda de antibiótico. No período anterior a referida data, somando-se as vendas de todas as filiais, foram dispensadas 1754 especialidades farmacêuticas contendo penicilinas, já no período posterior o total dispensado foi de 1000 unidades, o que representa uma redução de $42,98 \%$. Os resultados encontrados neste trabalho demonstram uma significativa redução da venda de antibióticos da classe das penicilinas, e também uma redução no consumo desenfreado de antibióticos por parte da população estudada.

Palavras-chave: Antibióticos. Resistência antimicrobiana. RDC 20/2011.

\section{Abstract:}

The antibiotics may be natural or synthetic compounds that are able to inhibit fungi and bacteria growth or cause their death. Besides being among the most dispensed drugs, they are also among the drugs that present higher frequency of irrational use in the world. This 
paper presents a qualitative, quantitative and descriptive study and also a field research, which aimed to carry out an analysis of the beta-lactam antibiotics dispense after "RDC No.20/2011" in a pharmacy chain in the city of Ponta Grossa, Paraná, Brazil. The research also aimed to identify customer consciousness regarding the mandatory of the prescription to buy antibiotics. It was performed the survey of beta-lactam antibiotics dispense rate in the period of one year before and one year after April 16th, 2013, date when Anvisa began to require from the pharmacies the electronic transmission of each antibiotic that is sold. In the period before that date, adding up all branches' sales, 1754 pharmaceutical products that contained penicillins were dispensed, whereas in the period after that date, the total dispensed of such products was 1,000 units, which represents a decrease of $42.98 \%$. The findings of this study demonstrate a significant reduction in the sale of antibiotics that belong to the class of the penicillins, and also a reduction in the unbridled use of antibiotics by the population studied.

Keywords: Antibiotics. Antimicrobial resistance. RDC 20/2011.

\section{INTRODUÇÃO}

Os medicamentos são um fator essencial na orientação das políticas de saúde e a principal escolha terapêutica para a melhora do quadro clínico do paciente. Dentre os medicamentos mais utilizados destaca-se o grupo dos antibióticos (GURGEL; CARVALHO, 2008; NAVES, 2008).

Os antibióticos podem ser compostos naturais ou sintéticos capazes de inibir o crescimento ou causar a morte de fungos ou bactérias. Estão entre os grupos mais dispensados, no entanto, estão também entre os fármacos, mundialmente, mais utilizados de forma irracional (GURGEL; CARVALHO, 2008).

Dentre os grupos dos antibióticos destacam-se as penicilinas, que pertencem à classe dos antibióticos beta-lactâmicos cuja semelhança na composição química (Figura 1) determina propriedades farmacológicas e mecanismos de ação análogos (BRUNTON; LAZO; PARKER, 2007; KONG; SCHNEPER; MATHEE, 2010).

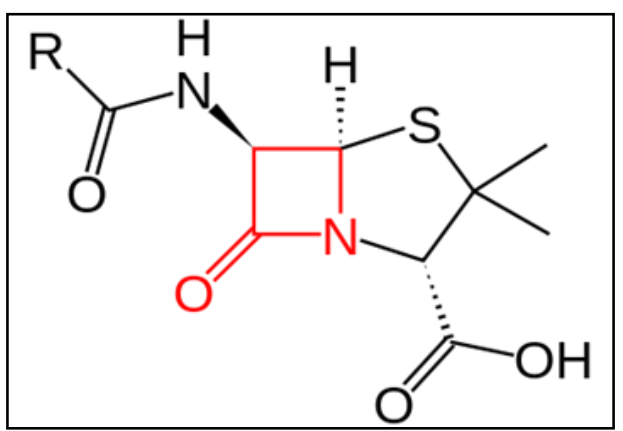

Fonte: Biomedicina Padrão (2014)

Figura 1 - Penicilina (anel beta-lactâmico em vermelho) 
As penicilinas atuam inibindo a etapa final da síntese da parede celular, sendo que este tipo de mecanismo de ação é responsável pela toxicidade seletiva, e consequentemente, a grande segurança do ponto de vista de toxicidade e teratogenicidade para o homem e mamíferos (DE LUCIA et al., 2007).

As penicilinas são entre os agentes antimicrobianos conhecidos, os mais eficazes e os menos tóxicos, tornando-os eletivos para o tratamento de grande número de infecções. Embora as penicilinas sejam os antibióticos mais seguros, são os que provocam, com maior frequência reações de hipersensibilidade (De LUCIA et al., 2007).

A classificação das penicilinas é feita considerando-se o seu espectro de atividade antimicrobiana. São classificadas em: a) naturais; b) penicilinase-resistentes; c) aminopenicilinas; e d) penicilinas de espectro ampliado (BRUNTON; LAZO; PARKER, 2007; BRASIL, 2014).

Algumas bactérias produzem uma enzima chamada penicilinase, uma betalactamase, enzima capaz de quebrar o anel beta-lactâmico. Em sua estrutura básica as penicilinas contêm esse grupo beta-lactâmico (Figura 1), a ruptura desse anel promove a inativação do antibiótico (BRUNTON; LAZO; PARKER, 2007).

Ainda de acordo com Brunton, Lazo e Parker (2007) a modificação estrutural na preparação dos antibióticos pode ser direcionada para evitar a ação da penicilinase, gerando estruturas resistentes ou não a essa enzima. Os inibidores de beta-lactamases, quando em associação com antimicrobianos beta-lactâmicos, ligam-se às beta-lactamases, evitam a hidrólise do anel beta-lactâmico e potencializam sua atividade (Brasil, 2014).

Desde que a penicilina foi descoberta por Alexander Fleming em 1928, o homem e a bactéria disputam uma corrida na qual a liderança vem se alterando o tempo todo. Porém o que se prevê, é que os antibióticos terminem superados pelas bactérias (GOMES, 2014).

Devido ao curto tempo de geração, minutos ou horas, as bactérias podem responder rapidamente as mudanças do ambiente. Quando antibióticos são introduzidos em um ambiente, as bactérias podem como resposta, tornarem-se resistentes a essas substâncias. A resistência aos antibióticos se desenvolve como uma consequência natural da própria habilidade da população bacteriana em se adaptar (SANTOS, 2004).

O uso indiscriminado de antibióticos aumenta a exposição bacteriana aos mesmos e a pressão seletiva, essa oportunidade facilita a aquisição de mecanismos resistentes, fato que se torna inevitável e irreversível. O uso intenso de antibióticos na medicina, na produção de alimentos para animais e na agricultura tem causado um aumento na resistência àquelas drogas em todo mundo (SANTOS, 2004). 
Deste modo, o uso inadequado foi se tornando um fato comum, porém calamitoso com o tempo. Para evitar a resistência microbiológica, os medicamentos devem ser usados de forma cuidadosa.

Para tentar amenizar tais problemas, a ANVISA aprovou uma nova norma para regulamentar a venda de antibióticos no Brasil. A RDC no 20/2011 que foi publicada no Diário Oficial da União (DOU) em 09/05/2011, revogando todas as resoluções anteriores sobre o tema (BRASIL, 2011).

A RDC nำ20/2011 modificou a forma de dispensação dos antibióticos, de modo que passou a ser um grupo de medicamentos controlado, isto é, somente dispensado mediante prescrição (BRASIL, 2011).

Diante disso, o presente trabalho teve como objetivo realizar uma análise da dispensação de antibióticos beta-lactâmicos antes e após a RDC 20/2011 em uma rede de farmácias do município de Ponta Grossa-Paraná, e identificar a percepção do cliente em relação à obrigatoriedade de prescrição para dispensação de antibióticos.

\section{MATERIAL E MÉTODOS}

Trata-se de um estudo qualitativo e quantitativo, descritivo, documental e de campo. Para atingir os objetivos propostos, coletaram-se informações em uma rede de farmácias do município de Ponta Grossa-PR, num total de seis lojas, distribuídas nos bairros de Nova Rússia, Oficinas, Sabará, Esplanada, Ronda e Cará-Cará.

Foi realizado o levantamento da frequência de dispensação de antibióticos da classe dos beta-lactâmicos, especificamente os do grupo das penicilinas, no período de um ano antes e um ano depois de 16 de abril de 2013, data em que a Anvisa passou a exigir das farmácias e drogarias, a transmissão eletrônica de cada venda de antibiótico no Sistema Nacional de Gerenciamento de Produtos Controlados (SNGPC).

Os dados foram levantados a partir do software da farmácia. Para esse estudo foram incluídos os principais antibióticos penicilâmicos, aminopenicilinas (amoxicilina e ampicilina), associados a inibidores das beta-lactamases e penicilina G. Foram excluídos da pesquisa, todos os antibióticos que não pertencem ao grupo das penicilinas, ou não são dispensados na farmácia, como os restritos a uso hospitalar. Os antimicrobianos do grupo das penicilinas são os mais vendidos na rede, com destaque para a amoxicilina que possui um elevado número de prescrições, fato esse, que de acordo com Poliesel e Bergê (2014) também é evidenciado por outros pesquisadores e por se tratar de um antimicrobiano de 
amplo espectro e baixa toxicidade, constitui o tratamento de primeira escolha para vários quadros infecciosos e confere maior segurança ao prescritor.

Para identificação da percepção do cliente em relação a obrigatoriedade da prescrição para antibióticos, foi realizada uma pesquisa de campo, utilizando um questionário, que foi aplicado de forma individual em uma sala apropriada. Participaram da pesquisa 180 clientes da rede de farmácias em estudo, sendo 30 de cada filial. Foram selecionados de forma intencional, indivíduos que utilizaram antibióticos durante o período de analise da pesquisa, ambos os sexos, acima de 18 anos, cliente da farmácia, e que aceitaram participar da pesquisa e assinaram o TCLE (Termo de Consentimento Livre e Esclarecido).

A coleta de dados foi realizada no período de 05 de março de 2015 ao dia 28 de março de 2015, após o projeto ter sido aprovado pelo Comitê de Ética em Pesquisa (CEP) do Centro de Ensino Superior dos Campos Gerais - CESCAGE, sob o n 973.426.

\section{RESULTADOS E DISCUSSÃO}

Para a realização da discussão dos resultados, a análise foi realizada em dois momentos. Inicialmente serão discutidos os dados relacionados à dispensação de antibióticos no estabelecimento farmacêutico, pesquisa documental, em seguida, serão apresentadas informações quanto à percepção dos clientes com relação à obrigatoriedade da prescrição para obtenção de fármacos do grupo dos antibióticos.

\subsection{Dados da dispensação de antibióticos no estabelecimento farmacêutico}

Foram coletados dados referentes às penicilinas disponíveis no local do referido estudo e que foram dispensadas durante o período de coleta de dados da pesquisa (Quadro 1).

Quadro 1 - Penicilinas dispensadas durante a coleta de dados da pesquisa

\begin{tabular}{|c|c|c|c|}
\hline $\begin{array}{c}\text { Penicilina } \\
\text { (via Oral) }\end{array}$ & $\begin{array}{c}\text { Concentração } \\
(\mathbf{m g})\end{array}$ & Forma Farmacêutica & Unidades ou volume \\
\hline \multirow{3}{*}{ Amoxicilina } & 500 & cápsulas & $15,18,21$ \\
\cline { 2 - 4 } & 875 & comprimidos & 14,20 \\
\cline { 2 - 4 } & 1000 & comprimidos & 10 \\
\cline { 2 - 4 } & 400 & pó/suspensão & $100(\mathrm{~mL})$ \\
\cline { 2 - 4 } & 250 & pó/suspensão & $150(\mathrm{~mL})$ \\
\hline Amoxicilina + Clavulanato & 875 & comprimidos & 14,20 \\
\cline { 2 - 4 } & 1000 & pó/suspensão & $70 / 140(\mathrm{~mL})$ \\
\hline Amoxicilina + Sulbactan & 875 & pó/suspensão & 14 \\
\cline { 2 - 4 } & 1000 & comprimidos & $30 / 60(\mathrm{~mL})$ \\
\hline Ampilicina & 500 & Forma Farmacêutica & Volume \\
\hline Penicilina (Injetável) & Concentração (mg) & $4 \mathrm{~mL}$ \\
\hline Penicilina & 1.200 .000 Ul & ampola injetável & \\
\hline
\end{tabular}

Fonte: $\mathrm{O}$ autor (2015) 
Foi selecionado de forma intencional o período de 16/04/12 à 16/04/13, isto é, a quantidade vendida um ano antes, que denominaremos de período A (anterior); e 16/04/13 à 16/04/14, quantidade vendida um ano de depois de 16/04/13, data em que a ANVISA passou a exigir das farmácias e drogarias, a transmissão eletrônica de cada venda de antibiótico, que denominaremos de período $\mathrm{P}$ (posterior).

No período A, somando-se as vendas de todas as filiais, foram dispensadas 1754 especialidades farmacêuticas contendo penicilinas, já no período $\mathrm{P}$, o total dispensado foi de 1000 unidades, o que representa uma redução de 42,98\%. Percentual esse, que demonstra maior eficiência no controle de antimicrobianos, após exigência da transmissão eletrônica.

Nas figuras 2 e 3 estão distribuídas respectivamente, a frequência das dispensações por unidade de especialidade farmacêutica e a variação entre os períodos por filial.

Foi possível verificar uma redução significativa em todas as filiais exceto na filial Nova Rússia onde houve um aumento de 25,12\%, fato que provavelmente está ligado à localização da mesma, visto que essa farmácia se encontra em frente a um hospital de referência na cidade.

Com o controle dos antibióticos, as pessoas que compravam antibióticos sem receita, passaram a procurar o hospital para consultas e obtenção de prescrição médica, ao deixarem o local, devido à facilidade, adquiriam seu medicamento na farmácia próxima ao mesmo, deixando assim de comprar em seu próprio bairro.

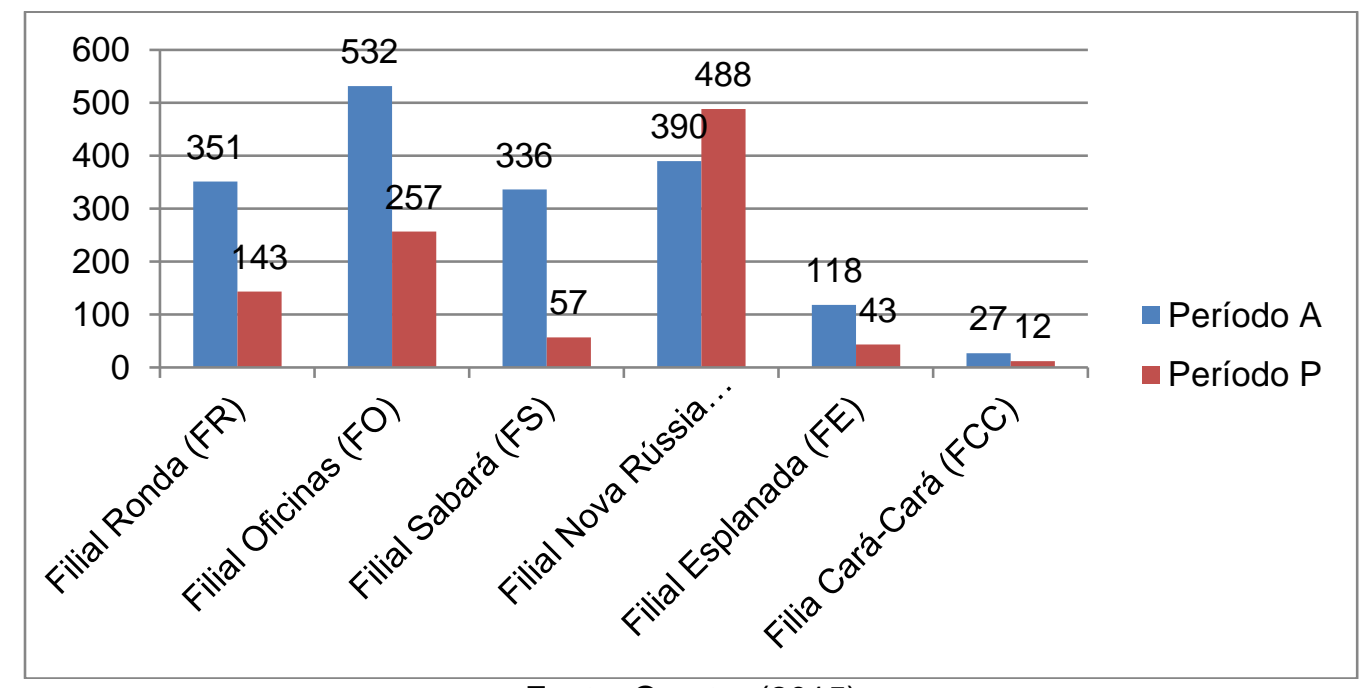

Fonte: O autor (2015)

Figura 2 - Frequência da dispensação de antibióticos em unidades por filial nos períodos A e P 


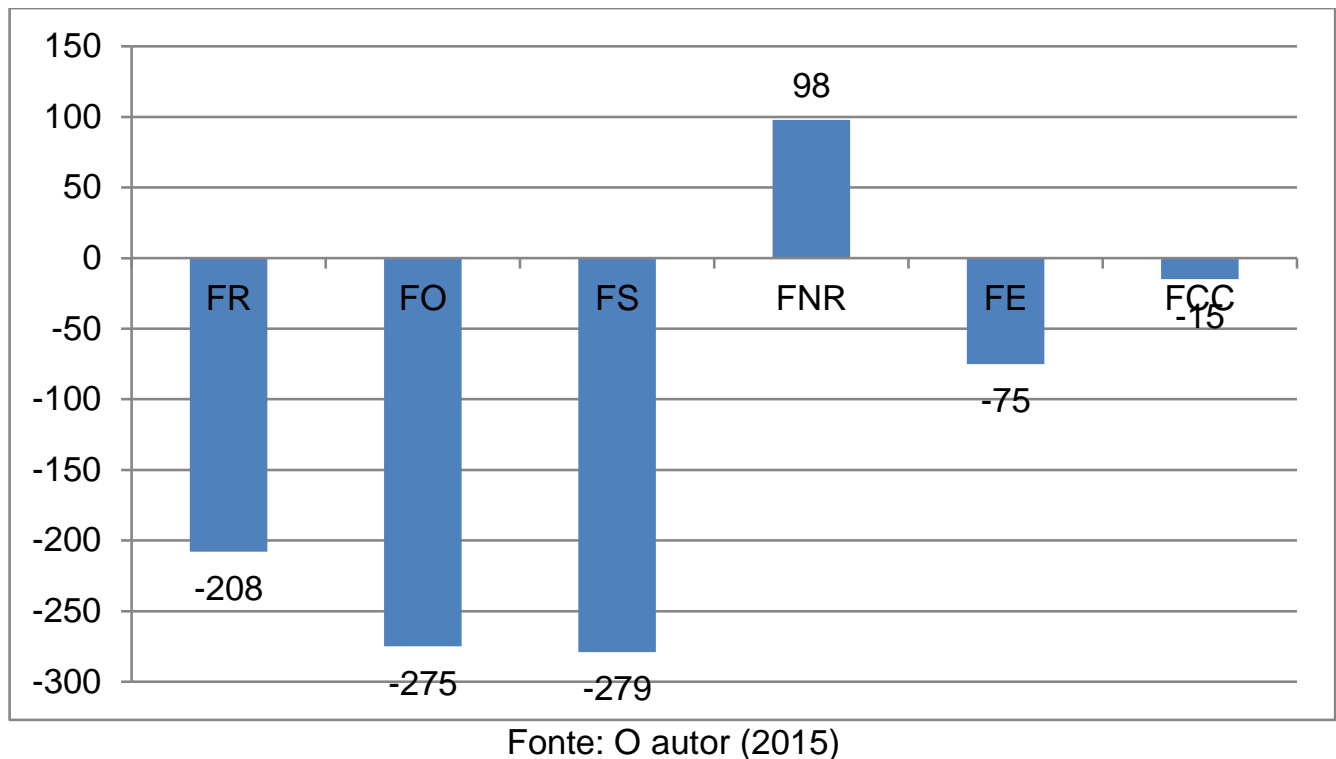

Figura 3 - Variação da dispensação de antibióticos em unidades por filial entre o período A e P

A filial que mais reduziu a dispensação de antibióticos foi a do Sabará que teve uma redução de $83,03 \%$, o que sugere que no período anterior ao controle, existia uma grande dispensação de antibióticos sem prescrição médica ou até mesmo elevada indicação ou indução a automedicação por parte dos balconistas.

A filial Esplanada teve uma redução de 63,55\%, a filial Ronda reduziu em 59,29\%, seguidas da filial Cará-Cará e Oficinas que tiveram respectivamente uma redução 55,55\% e $51,69 \%$. Fica claro que em todas as filiais, existia automedicação e indicação de antibióticos sem prescrição; a diferença na quantidade dispensada e na redução que ocorreu, pode estar relacionada a localização do estabelecimento e a diferença no perfil de clientes que consome os medicamentos.

\subsection{Dados Relacionados à percepção do cliente com relação ao uso de antibióticos}

Para atingir o objetivo proposto foi aplicado um instrumento de coleta de dados a 180 clientes do estabelecimento farmacêutico do referido estudo.

Do total 98 (54,45\%) são do gênero feminino e 82 (45,55\%) do gênero masculino, sendo o mais jovem com 18 anos, o mais idoso com 80 anos, portanto a média de idade foi 42,7 anos. Segundo Fleith et al. (2008), o maior consumo de medicamentos entre o sexo feminino pode estar ligado ao fato das mulheres possuírem uma maior preocupação com a saúde e procurarem mais os serviços de saúde do que os homens. 
Com relação ao grau de escolaridade, 90 (50\%) apresentaram ensino médio completo (tabela 1). Nos estudos de Bertoldi et al. (2004) e Sans et al. (2002), o nível de escolaridade não apresentou relação com a automedicação, porém o estudo de Mendes et al. (2004) revelou proporção mais elevada de automedicação nos indivíduos com formação universitária e nos que trabalhavam ou eram estudantes. Vilariano et al. (1998) em seu estudo demonstra que o acúmulo de conhecimento, tanto adquirido com as experiências de vida ou nas instituições educacionais, gera uma maior confiança naqueles que se automedicam.

Tabela 1- Grau de Escolaridade dos participantes da pesquisa

\begin{tabular}{lcc}
\hline \multicolumn{1}{c}{ Grau de Escolaridade } & $\boldsymbol{f}(\boldsymbol{n = 1 8 0 )}$ & $\%$ \\
\hline Sem escolaridade & 01 & 0,56 \\
\hline Ensino fundamental incompleto & 12 & 6,67 \\
\hline Ensino fundamental completo & 50 & 27,77 \\
\hline Ensino médio incompleto & 02 & 1,12 \\
Ensino médio completo & 90 & 50 \\
\hline Ensino Superior incompleto & 10 & 5,55 \\
\hline Ensino Superior completo & 15 & 8,33 \\
\hline Total & 180 & 100 \\
\hline
\end{tabular}

Fonte: $O$ autor (2015)

Antes da RDC 20/2011, 80,55\% (145) relataram que apresentavam o hábito de comprar antibióticos sem prescrição e 19,45\% (35) que não, sendo que, dos que costumavam a adquirir, $48 \%$ o faziam quase sempre (figura 4). A prática da automedicação é bastante comum no Brasil, devido ao difícil acesso à assistência médica pública e o fato de grande parcela da sociedade se encontrar na faixa da pobreza, não tendo condições financeiras para pagar um plano de saúde ou consulta particular. $\mathrm{O}$ baixo poder aquisitivo da população e a precariedade dos serviços de saúde contrastam com a facilidade de se obter medicamentos, sem pagamento de consulta e sem receita médica em qualquer farmácia, onde, não raro, se encontra o estímulo do balconista interessado em ganhar uma comissão pela venda (AQUINO, 2008). 


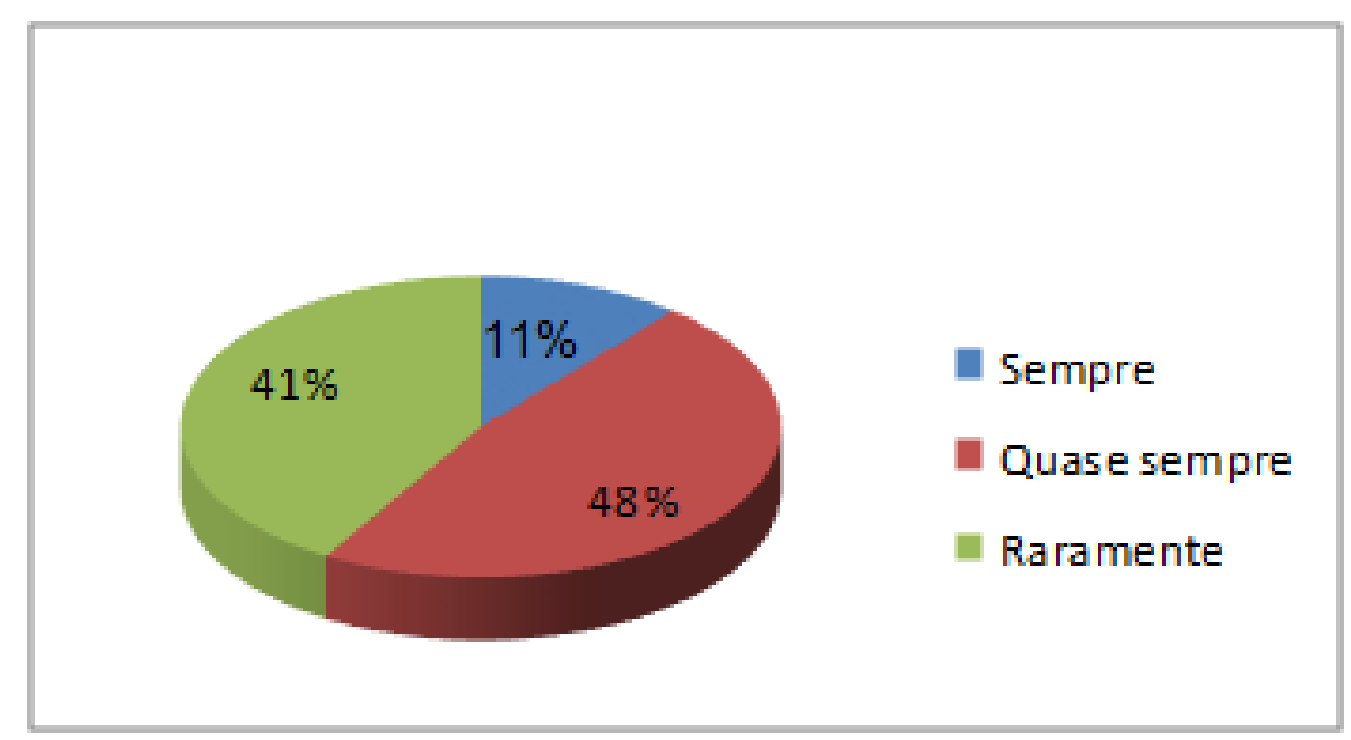

Fonte: O autor (2015)

Figura 4 - Frequência de utilização de antibióticos sem prescrição

A escolha do antibiótico pelos clientes sem prescrição ocorreu principalmente por orientação do farmacêutico e atendentes de farmácia, pois esses profissionais foram citados 116 e 37 vezes respectivamente.

Conforme Maier e Abegg (2007) 42,4\% dos farmacêuticos que trabalham em farmácias em Toledo-Pr relataram dispensar antibióticos sem prescrição médica. Ao estudar a conduta de comercialização no balcão das farmácias de Porto Alegre-RS, Facin e colaboradores (2005) revelaram que houve prescrição indevida de fármacos antimicrobianos e que os balconistas não estavam preparados para dar o correto encaminhamento às queixas apresentadas pelos usuários.

Dos clientes entrevistados, 9,1\% mencionaram que utilizaram o medicamento por indicação de um farmacêutico, baseado nos sintomas clínicos, e 9,1\% correspondiam à automedicação aliada à facilidade de aquisição (BRAOIOS et al., 2013).

Assim, também cabe destacar a prática da automedicação, pois 34 indivíduos relataram tal prática e uso de receita antiga foi citado 3 vezes por pesquisados e 2 declararam adquirir por meio de amigos ou vizinhos. De acordo com Naves, et al. (2008), a familiaridade do leigo com os medicamentos, as experiências positivas anteriores e a dificuldade de acesso a serviços de saúde são fatores que também contribuem para a automedicação.

Nota-se no Brasil, grande aumento no consumo de medicamentos pela população, fato que leva ao uso desnecessário ou errôneo, o que resulta em consequências sérias 
como reações alérgicas, intoxicações, efeitos colaterais indesejados, etc. Raras vezes esses sintomas são conhecidos pelo paciente, e este, quando não utiliza todo o medicamento, vai armazenando em casa, para posterior utilização (SOUSA; SILVA; NETO, 2008).

Com relação ao conhecimento dos problemas da utilização de um antibiótico sem prescrição 60\% (87) relataram não ter conhecimento e 40\% (58) conseguem apontar alguns problemas relacionados à medicação antibiótica sem prescrição (Tabela 2).

Tabela 2 - Problemas relatados da utilização de um antibiótico sem prescrição

Riscos Citados

Resistência bacteriana

Efeitos colaterais

Intoxicação

Reação alérgica

Risco à saúde

Dependência

Interação medicamentosa

Antibiótico inadequado
Frequência (no de vezes citado)

\section{0}

15

10

04

04

02

02

01

Fonte: O autor (2015)

De acordo com Bastiani e colaboradores (2005), a facilidade das pessoas se automedicarem, até certo modo, é inevitável e pode trazer situações nocivas à saúde do indivíduo como: efeitos adversos, reações alérgicas, intoxicação, alterações e aumento da resistência bacteriana no caso dos antibióticos.

Referente à livre opinião sobre a venda de antibióticos sem a retenção da receita, muitos clientes limitaram-se a responder apenas se eram contra ou a favor e outros não opinaram, seguem abaixo algumas das repostas, selecionadas de forma intencional devido a relevância:

"Sou a favor, por exemplo, o paciente que mora na zona rural, eles vão ter de ir até a cidade consultar para comprar o medicamento e é mais fácil ir a farmácia e comprar o medicamento com o farmacêutico, que desde que saiba o que está fazendo, deveria sim receitar. (Cliente $A)$ )" 
"Sou a favor pois, tenho um farmacêutico de confiança e o acesso ao médico ainda é difícil. (Cliente B)"

"Necessita haver mudança na saúde em geral. Apenas restringir a venda, sem a população ter acesso fácil a consulta médica não adianta. (Cliente C)"

"Desde que seja bem orientado pelo farmacêutico, não tem problema, respeitando o tempo de uso. (Cliente D)"

"Não sou contra a venda pois todas as vezes que precisei fui muito bem orientado pelo farmacêutico. Porém, penso que isto não é uma regra, pois nem todos seguem as orientações e podem acabar criando outro problema no organismo, ao invés de melhorar o que estava ruim. Na minha opinião, o paciente é que deveria fazer bom uso do medicamento. (Cliente E)"

"Para mim seria bom, por evitar de enfrentar fila para conseguir consultar. (Cliente F)"

"Acho errado e perigoso, mas nossos postos de saúde estão uma beleza, se for esperar estamos mortos, temos que nos virar como podemos. (Cliente G)"

"Se o acesso a consultas, principalmente na rede pública, fosse menos burocrático, seria a favor de toda receita retida. (Cliente $H$ )"

"Na falta do médico, vai na farmácia e o balconista indica o remédio bom para o caso.

(Cliente I)"

"É totalmente errado, porque a pessoa nem sabe o que tem e está tomando remédio por conta. (Cliente J)"

"É totalmente errado, pois, só o médico sabe qual medicamento é necessário para determinada doença ou infecção. (Cliente L)"

"Devem ser vendidos apenas com receita e esta deve ficar retida para poder haver controle do consumo de antibiótico. (Cliente M)"

"A venda de medicamento antibiótico, sem retenção de receita, não deve ser feita pois, muitas vezes, usamos medicamos sem saber sequer qual tipo de doença realmente temos e não sabemos o risco que corremos ao tomar remédios sem o devido cuidado. Já com a consulta de um especialista e realizando os devidos exames, temos ciência do quanto é importante consultar com um especialista antes de medicar-se (Cliente $N)$."

"Ruim, pois, as pessoas usam abusivamente esses medicamentos. (Cliente O)" 
De uma maneira geral, é possível notar opiniões divididas, mas a tendência maior foi de pensamentos favoráveis para a venda sem prescrição, provavelmente devido ao velho hábito da automedicação, é importante observar também a confiança no profissional farmacêutico. Em outros estudos é possível verificar que, a dificuldade e o custo para conseguir consulta médica, a limitação do poder prescritivo relacionado a poucos profissionais de saúde, a falta de regulamentação e fiscalização daqueles que administram o medicamento, são algumas das razões que levam o indivíduo à automedicação (DAMASCENO et al., 2007).

Com relação à redução da utilização de antibióticos após a RDC 20/2011, 88,9 \% (129) relataram ter diminuído a sua utilização e apenas $11,8 \%$ (16) não conseguiram reduzir. Referente a frequência da procura do médico após a RDC 20/2011, 66,20\% (96) relataram que não procuram o médico com maior frequência e 33,80\% (49) acabaram consultando o profissional com maior frequência. Resultados que demonstram impacto, da RDC 20/2011, no consumo exacerbado de antimicrobianos, principalmente após implantação da escrituração eletrônica no SNGPC.

\section{CONCLUSÃO}

Os resultados encontrados neste trabalho demonstram uma significativa redução da venda de antibióticos da classe das penicilinas, e também uma redução no consumo desenfreado de antibióticos por parte da população estudada. O que comprova a importância da RDC 20/2011 no uso racional dos antimicrobianos.

O estudo apresentou limitações devido à escolha de apenas uma classe de antibióticos. Assim, acredita-se ser de grande importância o desenvolvimento de outros estudos incluindo mais classes de antibióticos.

Este trabalho contribuiu para um melhor conhecimento da percepção do cliente, podendo ser observado uma preferência pela automedicação, evidenciado a importância de uma orientação profissional. Frente a isso, o farmacêutico sendo um profissional capacitado, tem um importante papel na conscientização do uso racional de antibióticos, evitando possíveis riscos para a saúde da população e contribuindo para prevenção da resistência antimicrobiana. 


\section{REFERÊNCIAS}

AQUINO, D.S. Por que o uso racional de medicamentos deve ser uma prioridade? Ciência e Saúde Coletiva. Rio de Janeiro, v. 13, p. 733-736, 2008.

BASTIANI, A.; ABREU, L.C.; SILVEIRA, K.L.; LIMBERGER, J.B. O Uso abusivo de medicamentos. Disciplinarum Scientia: Série Ciências da Saúde. Santa Maria, v. 6, n. $1,2005$.

BERTOLDI, A.D.; BARROS, A.J.D.; HALLAL, P.C.; LIMA, R.C. Utilização de medicamentos em adultos: prevalência e determinantes individuais. Rev. Saúde Pública. São Paulo, v. 38 , n. 2, p. 228-238, 2004.

BIOMEDICINA PADRÃO. Staphylococcus aureus resistente à meticilina (MRSA). Disponível em: <http://www.biomedicinapadrao.com.br/2012/02/staphylococcus-aureusresistente.html>. Acesso em: 30 abr. 2014.

BRAOIOS, A.; PEREIRA A.C.S.; BIZERRA, A.A.; POLICARPO, O.F.; SOARES, N.C.; BARBOSA, A.S. Uso de antimicrobianos pela população da cidade de Jataí, GO. Brasil. Rev. Ciência \& Saúde Coletiva. Rio de Janeiro, v. 18, n. 10. p. 3055-30360, 2013.

BRASIL. Agência Nacional de Vigilância Sanitária - ANVISA. Antimicrobianos - Bases Teóricas e uso Clínico. Disponível em: <http://www.anvisa.gov.br/servicosaude/controle/rede_rm/cursos/rm_controle/opas_web/ modulo1/conceitos.htm>. Acessado em: 20 abr. 2014.

BRASIL. Agência Nacional de Vigilância Sanitária - ANVISA. Informe técnico sobre a RDC №20/2011. Brasília, 17 de junho de 2011. Disponível em <http://www.anvisa.gov.br/sngpc/Informe_Tecnico_Procedimentos_RDC_n_20.pdf>. Acesso em: 11 maio 2015

BRUNTON, L. L.; LAZO, J. S.; PARKER, K. L. Goodman \& Gilman. As bases farmacológicas da terapêutica. 11. ed. Rio de Janeiro: McGraw-Hill Interamericana do Brasil, 2007. 
DAMASCENO, D.D.; TERRA, F.S.; ZANETTI, H.H.V.; D'ANDRÉA, É.D.; SILVA, H.L.R.; LEITE, J.A. Automedicação entre graduandos de enfermagem, farmácia e odontologia da Universidade Federal de Alfenas. REME: Revista Mineira de Enfermagem. Minas Gerais, v. 11, 2007.

DE LUCIA, R.; OLIVEIRA-FILHO, R.M.; PLANETA, C.S.; GALLACCI, M.; AVELLAR, M.C.W. Farmacologia integrada. 3. ed. Rio de Janeiro: Revinter, 2007.

FACIN, M.A.; FELIX, E.; HADLICH, E.; SCHMITZ, P.S.K.; MUXFELDT, R.A.; PEREIRA, R.P.; MENGUE, S.S. Condutas de balcão nas farmácias de Porto Alegre (Brasil), mediante apresentação de um caso de dor de garganta. Acta Farm. Bonaerense. Buenos Aires, v. 24, n. 2, p. 261-265, 2005.

FLEITH, V.D.; FIGUEIREDO, M.A.; FIGUEIREDO, K.F.L.R.O.; MOURA, E.C. Perfil de utilização de medicamentos em usuários da rede básica de saúde de Lorena, SP. Ciência \& Saúde Coletiva. Rio de Janeiro, v. 13, p. 755-762, 2008.

GOMES, J.V. Superbactérias e resistência a antibióticos: Curso de bio-atualidades.

Disponível em: <http://www.libertaria.pro.br/antibioticos_intro.htm>. Acesso em: 30/04/2014.

GURGEL, T.C.; CARVALHO, W.S. A assistência farmacêutica e o aumento da resistência bacteriana aos antimicrobianos. Lat Am J Pharm. São Paulo, v. 27, p. 118-23, 2008.

KONG, K.-F.; SCHNEPER, L.; MATHEE, K. Beta-lactam antibiotics: from antibiosis to resistance and bacteriology. APMIS : acta pathologica, microbiologica, et immunologica Scandinavica, v. 118, n. 1, p. 1-36, 2010.

MAIER, C.R.; ABEGG, M.A. Avaliação da utilização de antibióticos por profissionais de saúde e pela população na cidade de Toledo, Paraná, Brasil. Arq. Ciênc. Saúde Unipar. Umuarama, v. 11, n. 1, p. 19-26, 2007.

MENDES, Z.; MARTINS, A.P.; MIRANDA, A.C.; SOARES, M.A.; FERREIRA, A.P.; NOGUEIRA, A. Prevalência da automedicação na população urbana portuguesa. Revista Brasileira de Ciências Farmacêuticas. São Paulo, v. 40, n. 1, 2004. 
NAVES, J.O.S.; CASTRO, L.L.C.; MELO, G.F.; GIAVONI, A.; MERCHÁN-HAMANN, E. Práticas de atendimento a DST nas farmácias do Distrito Federal, Brasil: um estudo de intervenção. Cadernos de Saúde Pública. Rio de Janeiro, v. 24, n. 3, p. 577-586, 2008.

POLISEL, C.G.; BERGÊ, R.S. Avaliação da conformidade de prescrições médicas e dispensação de antimicrobianos. Rev Bras Promoç Saúde. Fortaleza, v. 27, n. 1, p. 2128, 2014.

SANS, S.; PALUZIE, G.; PUIGA, T.; BALAÑÁ, L.; BALAGUER-VINTRÓ, I. Prevalencia del consumo de medicamentos en la población adulta de Cataluña. Gaceta Sanitaria. Barcelona, v.16. p. 121-30, 2002.

SANTOS, N.Q. A resistência bacteriana no contexto da infecção hospitalar. Texto \& Contexto Enfermagem. Santa Catarina, v. 13, p. 64-70, 2004.

SOUSA, H.W.O.; SILVA, J.L.; NETO, SILVA, M.S. A Importância do Profissional Farmacêutico no Combate à Automedicação no Brasil. Revista Eletrônica de Farmácia. Goiás, v.5, n. 1, 2008.

VILARINO, J.F.; SOARES, I. C.; SILVEIRA, C. M.; RÖDEL, A. P. P.; BORTOLI, R.; LEMOS, R.R. Perfil da automedicação em município do Sul do Brasil. Revista Saúde Pública. São Paulo, v. 32, n. 1, p. 43-49, 1998. 